\title{
ERRATUM
}

This paper which appeared in Vol 11:16 p. 1145-1146 has been reprinted due to an error with the Figures. The corrected version is printed below:

\section{The coexistence of acicular ferrite and bainite in an alloy-steel weld metal}

J. R. YANG, C. C. YANG, C. Y. HUANG

Institute of Materials Science and Engineering, National Taiwan University, Taipei, Taiwan

For a multirun weld metal the fusion zone can be classified into two main components: the primary zone obtained during cooling of the weld from the liquidus and the secondary microstructure (commonly called the reheated zone) obtained during the deposition of further weld metal. The primary zone usually consists of large columnar austenite grains at high temperatures. On the other hand, the reheated zone of a multirun weld is nominally divided into austenite coarse-grained and fine-grained regions, depending on the peak temperature to which they are exposed. The effect of the grain size of prior austenite on the acicular ferrite transformation is significant. It has been shown [1] that if the primary microstructure of the weld deposit consists essentially of acicular ferrite, then the acicular ferrite can again be obtained in the reheated homogenized weld metal when the austenite grain size is relatively large. However, classical sheaf-like bainitic ferrite can form as the austenite grain size is small. Although Babu and Bhadeshia [2] reported that the acicular ferrite and bainite can coexist (Fig. 1), there

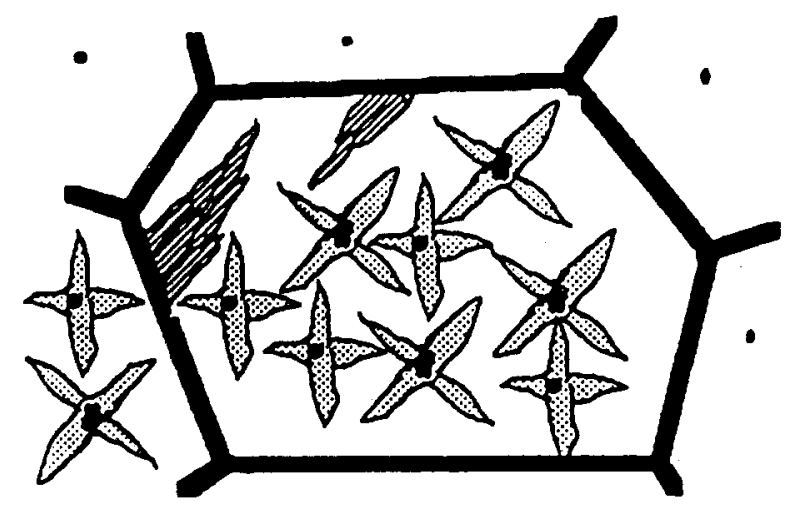

Figure 1 Schematic diagram showing the coexistence of acicular ferrite and bainite [2]. The inclusions (represented by the small round particles) are the nucleation sites for acicular ferrite. On the other hand, the prior austenite grain boundaries serve as the nucleation sites for bainite. is still no metallographic study to support this point of view. The purpose of this study was to examine the conditions under which the acicular ferrite and bainite coexist in an alloy-steel weld metal (Table I).

In order to obtain accurate temperatures during heat treatments, the processes were carried out in a Theta Industries high-speed dilatometer. The specimens for dilatometry were machined from the homogenized weld metal. The specimens were $3 \mathrm{~mm}$ diameter cylindrical rods of length $15 \mathrm{~mm}$, electroplated with a $7 \mu \mathrm{m}$ layer of nickel, to provide constraint and avoid surface nucleation and surface degradation effects. After austenitization in an atmosphere of pure helium (carried out in the dilatometer) at 900,1050 and $1200{ }^{\circ} \mathrm{C}$ for $10 \mathrm{~min}$, the specimen chamber was evacuated to facilitate quenching to different isothermal transformation temperatures by means of a controlled high-pressure helium jet directed both radially and axially at the specimen. After isothermal treatments the specimens were cooled rapidly to ambient temperature. Samples for the optical metallographic study were obtained from dilatometric specimens. They were manually polished, and etched with nital plus picral.

Austenite grain sizes for specimens austenitized at 900,1050 and $1200^{\circ} \mathrm{C}$ were about 15,38 and $55 \mu \mathrm{m}$, respectively. For a series of heat treatments it was found that as the isothermal transformation was kept at $420^{\circ} \mathrm{C}$ for $30 \mathrm{~min}$, only a small amount of austenite was untransformed, and was subsequently retained and/or partially transformed to martensite after rapid cooling to room temperature. The microphases (martensite or austenite) were lightly etched, and appeared as fine dispersions of islands among the non-parallel plates of acicular ferrite or between the parallel plates of bainitic ferrite. In this circumstance isothermal transformation from austenite with different grain sizes would lead to clearly seen features for the present metallographic study.

TABLE I Chemical composition (in wt \%) of the alloy-steel weld metal

\begin{tabular}{llllllllllllll}
\hline $\mathrm{C}$ & $\mathrm{Si}$ & $\mathrm{Mn}$ & $\mathrm{Ni}$ & $\mathrm{Mo}$ & $\mathrm{Cr}$ & $\mathrm{V}$ & $\mathrm{S}$ & $\mathrm{P}$ & $\mathrm{Al}$ & $\mathrm{Ti}$ & $\mathrm{Nb}$ & $\mathrm{O}$ & $\mathrm{N}$ \\
\hline 0.034 & 0.43 & 1.80 & 2.48 & 0.57 & 0.05 & 0.01 & 0.005 & 0.009 & 0.01 & 0.02 & 0.01 & 0.0396 & 0.0061 \\
\hline
\end{tabular}



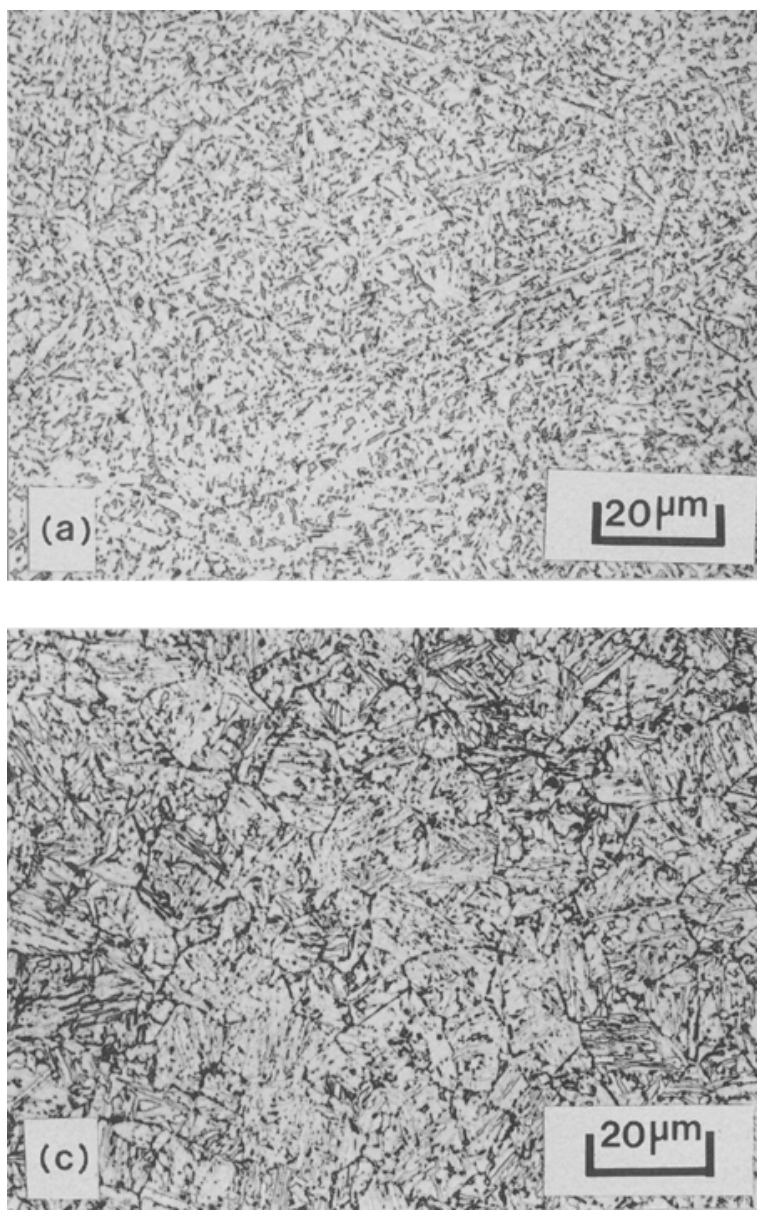

The distinct optical micrographs are shown in Fig. 2. Fig. 2a shows the very large volume fraction of acicular ferrite obtained after austenitization of weld metal at $1200^{\circ} \mathrm{C}$ for $10 \mathrm{~min}$ followed by isothermal transformation at $420^{\circ} \mathrm{C}$ for $30 \mathrm{~min}$. The micrograph clearly demonstrates the interlocking characteristic of acicular ferrite, which comes into existence because acicular ferrite nucleates intragranularly at inclusions within large austenite grains. On the other hand, Fig. $2 \mathrm{c}$ shows the very large volume fraction of bainite obtained after austenitization of weld metal at $900^{\circ} \mathrm{C}$ for $10 \mathrm{~min}$ followed by isothermal transformation, also at $420^{\circ} \mathrm{C}$ for $30 \mathrm{~min}$. The micrograph shows that the sheaves of bainite grow from grain boundaries, swamping the interior region of small austenite grains. The striking micrograph in Fig. 2b plainly confirms that acicular ferrite coexisted with bainite (feather-like sheaf structure) after austenitization of weld metal was carried out at

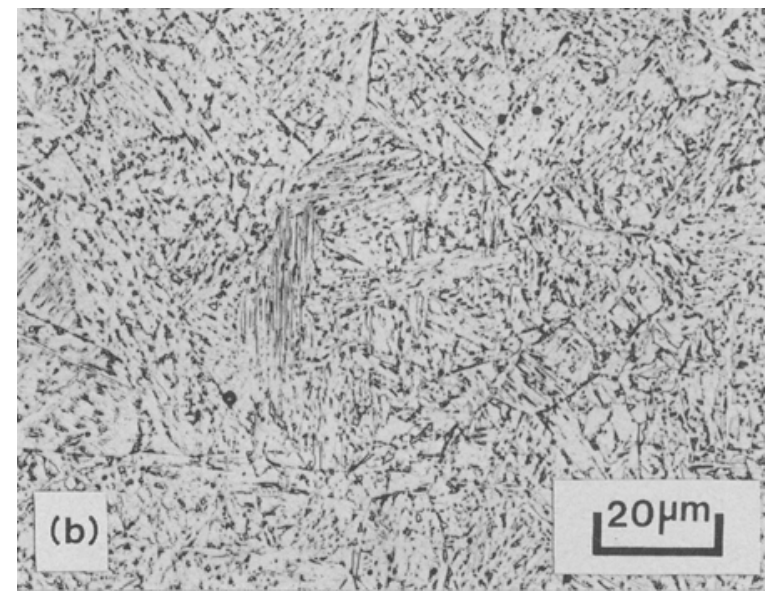

Figure 2 Optical mircographs: (a) very high volume fraction of acicular ferrite after austenitization of weld metal at $1200^{\circ} \mathrm{C}$ for $10 \mathrm{~min}$ followed by isothermal transformation at $420^{\circ} \mathrm{C}$ for $30 \mathrm{~min}$; (b) very high volume fraction of acicular ferrite with a certain amount of bainite obtained after austenization of weld metal at $1050^{\circ} \mathrm{C}$ for 10 min followed by isothermal transformation as in (a); and (c) very high volume fraction of bainite obtained after austenitization of weld metal at $900^{\circ} \mathrm{C}$ for $10 \mathrm{~min}$ followed by isothermal transformation as in (a).

$1050{ }^{\circ} \mathrm{C}$ for $10 \mathrm{~min}$ followed by the same isothermal transformation at $420^{\circ} \mathrm{C}$ for $30 \mathrm{~min}$. The result indicates that intergranularly nucleated bainite and intragranularly nucleated acicular ferrite can form simultaneously as the grain size of the prior austenite of the weld metal is medium. This study also emphasizes that the volume fractions of bainite and acicular ferrite should depend on the relative amounts of austenite grain boundary and intragranular nucleation sites available.

\section{References}

1. J, R. YANG and H. K. D. H. BHADESHIA, J. Mater. Sci. 26 (1991) 839.

2. S. S. BABU and H. K. D. H. BHADESHIA, Mater. Sci. Technol. 6 (1990) 1005.

Received 16 September 1991 and accepted 6 February 1992 